\title{
1579 Tarihli Mufassal Tahrir Defterine Göre Sigetvar Nahiyesi'nde Sosyal ve İktisadi Hayat
}

\section{Social and Economic Life in the Szigetvar Nahiyesi According to Cadastral Record Book Dated 1579}

\author{
Hanife $\mathrm{ALACA}^{1}$ (])
}

${ }^{1}$ Sorumlu yazar/Corresponding author: Hanife Alaca (Dr. Öğr. Üyesi),

Batman Üniversitesi, Fen-Edebiyat Fakültesi, Tarih Bölümü, Batman, Türkiye

E-posta: h.alaca67@gmail.com

ORCID: 0000-0002-8243-7278

Başvuru/Submitted: 02.07 .2020

Revizyon Talebi/Revision Requested:

12.08.2020

Son Revizyon/Last Revision Received:

01.09.2020

Kabul/Accepted: 17.02.2021

Online Yayın/Published Online: 02.04.2021

Atıf/Citation: Alaca, Hanife. "1579 Tarihli Mufassal Tahrir Defterine Göre Sigetvar Nahiyesi'nde Sosyal ve İktisadi Hayat." Türkiyat Mecmuası-Journal of Turkology 31, 1 (2021): 33-45

https://doi.org/10.26650/iuturkiyat.763339 öz

Sigetvar, I. Süleyman'ın yaptığı son sefer sonucunda 1566 yılında Osmanlı topraklarına katılmış Macaristan'da bir kaledir. Fethedildikten sonra Budin Eyaleti'nin bir sancağı olan Sigetvar daha sonra müstakil bir eyalet durumuna gelmiştir.

Bu makalenin amacı, arşivde bulunan 1579 yılına ait ilk mufassal tahrir defteri ışığında, reayanın hukuki durumu ve nüfusu hakkında bilgiler sunmaktır. Böylece, Sigetvar'ın Osmanlı hâkimiyetine geçmesi ile birlikte burada Osmanlı hâkimiyeti teşekkülü hakkında bilgi sahibi olunması amaçlanmaktadır.

Çalışmanın ana kaynağını Almanya Arşivi'nde "Munich Collections" da bulunan 1579 tarihli 138 Numara ile kayıtlı mufassal tahrir defteri oluşturmaktadır. III. Murad dönemine ait olan defterin ilk sayfasında "Defter-i Mufasall-ı Liva-i Sigetvâr bi- Dergâh-ı Âlî"i ibaresi yer almaktadır. Bu defterde, 1579 yılında Osmanlı hâkimiyeti altında bulunan Sigetvar'ın idarî yapısı, nüfus, iskân, yetiştirilen ürünler ve alınan vergiler hakkında ayrıntılı bilgiler mevcuttur.

Anahtar kelimeler: Osmanlı Devleti, Sigetvar, Nahiye, Sancak, Tahrir Defterleri

\section{ABSTRACT}

Sigetvar is a fortress in Hungary and it was added to the Ottoman lands in 1566 as a result of the last expedition made by I. Süleyman. After being conquered, Sigetvar, a sanjak of Budin Province, later became a detached state.

The purpose of this article is to provide information about the legal status and population of Muslim and non-Muslim reaya in Sigetvar in the light of the detailed book of 1579. Thus, with the transition of Sigetvar to Ottoman domination, here is to give information about the Ottoman domination organization.

The main source of our work is the registered grand registry book with the number 138 in 1579 in the "Munich Collections" in the German Archive. On the first page of the book belonging to the III. Murad period, the phrase "Defter-i Mufasall-ı Liva-i Sigetvâr bi- Dergâh-ıÂlî"'islocated.

This book contains detailed information about the administrative structure of Sigetvar, which was under Ottoman rule in 1579, population, settlement, products grown and taxes levied. As it is known, local history studies are very important in revealing the administrative organization, social and economic situation of a region.

Keywords: Ottoman State, Sigetvar, Nahiye, Sancak, Tahrir Register 


\section{EXTENDED ABSTRACT}

The focus of this study is Szigetvar that was added to the Ottoman lands as a result of Suleiman I's last military expedition. Szigetvar is a fortress in Hungary and was conquered in 1566. In this study, the order that was set up by the Ottoman State in Szigetvar after its conquest is addressed.

The aim of this study is to present information regarding the judicial state of the rayah in Szigetvar its population in the light of the review of the first discovered cadastral record book dated 1579. Therefore, it is aimed to have knowledge of the organization of the Ottoman dominance in Szigetvar with its fall under Ottoman rule.

Administrative structure of Szigetvar: Szigetvar district was established after 1566 when it fell under the Ottoman administration. In 1579, the district was composed of Szigetvar, Gorezgal, Siklos, and Hagan boroughs. With the conquest of Kanije in 1600, Kanije state was established and Szigetvar became a district of this state. Szigetvar remained as a district of Kanije state until 1688 when the Ottoman rule came to an end.

63 villages, 1 ranch, and 13 estates were recorded in Sizgetvar district in 1579. There were 762 households in total in the district. There are different views regarding the calculation of the number of households in the studies on population during the Classical era of the Ottoman State. The most accepted of these views is the method determined by Omer Lutfi Barkan as multiplying the tax section with 5. Therefore, we used the method of household $x 5=$ estimated population to obtain the estimated population of a settlement. Accordingly, the estimated population of Szigetvar district was 3.810 people. Among the mentioned population, there are even a few Muslims. The fathers' names of 3 Muslims in the Kostanci Village were Abdullah; thus, it seems that they accepted Islam and became Muslims later.

Economic structure of Szigetvar: The basic economic element in the agricultural area in the Ottoman State was agricultural products. Most of the income in Szigetvar district was earned from agricultural products. The primary agricultural products were wheat, meslin, linen, cabbage, sir, haricot bean, giyah, and cannabis. It is also seen that other agricultural activities were done such as vegetable gardens, fruits, and vine cultivation. The total income earned from agricultural production was 147.674 silver coins. It is seen that animal breeding in Szigetvar district included apiculture and henazir. The total income earned from this tax type was 19.143 silver coins.

Commercial and Industrial Activities: what distinguishes between the structure of a city and a village is the commercial and industrial activities. As known, city is a large settlement where most of its population deals with commercial, industrial, and administrative businesses. Mill, the first type of commercial and industrial taxes that we will review, is recorded as "resm-i asiyab". The amount of the tax taken from the mill was 175 silver coins in total. The other significant type of tax in the district was "resm-i hime". It was the tax taken on wood. The total amount taken from this type of tax in Szigetvar district was 9.307 silver coins. 
Resm-i Fucu: non-Muslims who produced must had to give one tenth of the must to the timar holder. The timar holder would seal the must barrels to sell and announce manapolye by prohibiting must sales. According to this, the process called manapolye would take two months and ten days and it was stated that it could not be longer than that. The income earned from the Fucu was 1.342 silver coins.

Citizenship and Accidental Taxes: Citizenship tax is a tax that is not based on production but taken from the individuals depending on their judicial status (married or single, Muslim or non-Muslim) and the land they saved. These taxes in Szigetvar district were resm-i kapu and resm-i cift. The total amount obtained from the Citizenship tax was 38.166 silver coins. Accidental taxes were land title, deştbani, arus and regency. The total amount of income from these taxes was 23.287 silver coins.

In conclusion, it is known that the basic source for the local studies of XV. and XVI. centuries are cadastral record books. These books are the primary sources referred to reveal the administrative, economic, social structures and settlement process of a district that forms the basis of the Ottoman rural structure. In this context, the book we studied on is the first cadastral record book of Szigetvar and; thus, it is possible to reveal the order that the Ottomans set in Szigetvar.

It is seen that the Ottoman rule was settled in Szigetvar district in 1579. Almost all of the villages of the district were inhabited. Most of the population was settled in the rural areas as a characteristic of the agricultural society. Non-Muslims consisted of almost all of the population in the district. It is seen that the Ottoman State did not inhabit Turkish population as a part of its settlement policy in the Balkans. The fathers' names of 3 Muslims in the Szigetvar district were Abdullah; thus, it seems that they accepted Islam and became Muslims later and they were not subject to any settlement policy.

Moreover, there is a record titled "Varoş-1 Szigetvar, maa çiftlikha ve ispençe-i kıbtıyan" on Szigetvar district. It is seen that the Muslim population was formed as a result of conversions as the fathers' names of 45 registered citizens' was Abdullah. In addition, it is significant that the fathers' names of 14 people in Mehmed bin Bayezid neighborhood and 12 people in Veli bin Ali neighborhood.

After the Ottoman conquest, foundations were established in Szigetvar. It can be stated that the existence of these foundations had a significant effect on Szigetvar's gaining the characteristics of an Ottoman city.

The economic structure of Szigetvar district consisted of agriculture. The income earned from agriculture was $83 \%$ of the total income of the district. Citizenship and accidental taxes were the second income source after the agriculture tax and constituted $11,5 \%$ of the income. The income earned from commercial and industrial products was the third with 5,3\% percentage. 


\section{Giriş}

Macaristan'da Baranya idari birimine bağlı bir şehir olan Sigetvar "ada kale” anlamına gelmektedir. ${ }^{1}$ Sigetvar Macaristan'ın güneybatısında konumlanmış, Macaristan ve beşinci büyük şehri olan Peçuy'un batısında bir kaledir. Sigetvar adı Macar kaynaklarında "Szigeti (Szijet)" olarak geçmektedir. ${ }^{2}$ Günümüzde "Zigetvar” olarak adlandırılan bölge, Türk kaynaklarında "Sigetvar" olarak kaydedilmiştir. ${ }^{3}$

Sigetvar, I. Süleyman'ın on üçüncü ve son seferi sonucunda fethedilmiştir. I. Süleyman, Macaristan seferi sırasında Eğri tarafına gidilmesini kararlaştırmıştır. Fakat Sigetvar Beyi “Zerniski Mokloş”un (Zrinyi Mikloş), Tırhala sancakbeyi ve oğlunu öldürmesi üzerine seferin yönü değiştirilerek Sigetvar Kalesi üzerine sefer yapılmasına karar verilmiştir. "Kont Zerini” tarafından müdafaa edilen kale, Osmanlılar tarafından otuz dört günlük bir kuşatmadan sonra $1566^{5}$ yılında fethedilmiştir. ${ }^{6}$ Böylece, Sigetvar kuşatması 7 Eylül 1566 yılında gerçekleşen zaferle sonuçlandırılmıştır. ${ }^{7}$ I. Süleyman, Sigetvar seferine bizzat ordununun başında katılmış ve Sigetvar'da şehit olmuştur. ${ }^{8}$

Osmanlı tarihinde Sigetvar, 1566 yılında I. Süleyman'ın son seferi olması ve burada şehit olması dolayısıyla zihinlerde yer almıştır. Bu çalışmada, Osmanlı zaferi sonrasında, Sigetvar'ın Osmanlı hâkimiyeti altındaki idari yapısı, nüfusu, sosyal ve iktisadi hayatı konu edilmiştir. Çalışmada, 138 numaralı mufassal tahrir defterinden elde edilen veriler doğrultusunda değerlendirme yapılacaktır.

Sigetvar'a ait Başbakanlık Osmanlı Arşivi'nde iki adet tahrir defteri mevcuttur. Bunlardan ilki Sigetvar'ın ilk tahrir kayıtlarını içeren 503 numarada kayıtlı ve M. 1570 (H.978) yılına ait defterdir. Defter, siyakat yazı türünde yazılmış olup, 160 sayfadan oluşmaktadır. Defterin üçüncü sayfasında II. Selim'in tuğrası bulunmaktadır. ${ }^{9}$

Şemseddin Sami, Kâmus-ı Alâm, 4, (İstanbul: Mihran Matbaası, 1311), 2586.

Geza, "Sigetvar", 157.

İsmail Hakkı Uzunçarşılı, Osmanlı Tarihi, II, (Ankara, TTK Yayınları, 1983), 412.

Uzunçarşı11, Osmanlı Tarihi, 412.

Sigetvar'ın fethi ile ilgili daha geniş bilgi için bkz. Selânikî Mustafa Efendi, Tarih-i Selânikî I (971-1003/15631595), haz. Mehmet İpşirli, (Ankara: TTK Yayınları, 1999); Peçevi İbrahim Efendi, Peçevi Tarihi I, haz. Bekir Sitkı Baykal, (Ankara: Kültür Bakanlığı Yayınları, 1992); Ahmet Önal, Kanunî'nin Son Seferi (Sigetvar 1566), (İstanbul: Yeditepe Yayınevi, 2019); Feridun Ahmed Bey, Nüzhet-i Esrârü'l-Ahyâr Der-Ahbâr-l Sefer-i Sigetvar / Sultan Süleyman'ın Son Seferi, haz. H. Ahmet Arslantürk-Günhan Börekçi,(İstanbul: Zeytinburnu Belediyesi Kültür Yayınları, 2012); Kübra Naç, Âgehî’nin Fetih-nâme-i Kal'a-i Sigetvar'1 (İnceleme-Tenkitli Metin), Basılmamış Yüksek Lisans Tezi, Fatih Üniversitesi Sosyal Bilimler Enstitüsü, İstanbul: 2013. Ayrıca, Başbakanlık Osmanlı Arşivi 5 Numaralı Mühimme Defteri’nde Sigetvar seferi, özellikle de Sigetvar seferine çıkan ordunun menzilleri hakkında kayıtlar mevcuttur. Örneğin, bkz. Osmanlı Arşivi (BOA) Cumhurbaşkanlığı Devlet Arşivleri, Osmanlı Arşivi Daire Başkanlığı, Mühimme Defterleri (A.DVNSMHM), No: 5, (h.1511), 551; h. (1518), 554.

7 Ahmet Önal, Kanunî̀nin Son Seferi (Sigetvar 1566), (İstanbul: Yeditepe Yayınevi, 2019), 312.

8 Selânikî Mustafa Efendi, Tarih-i Selânikî I (971-1003/1563-1595), haz. Mehmet İpşirli, (Ankara: TTK Yayınları, 1999), 39.

9 Osmanlı Arşivi (BOA) Cumhurbaşkanlığı Devlet Arşivleri, Osmanlı Arşivi Daire Başkanlığı, Tapu Tahrir Defterleri ( TT.d), 503,3. 
Sigetvar'a ait ikinci tahrir defteri 638 numarada kayıtlıdır. Defterin ilk sayfasında III. Murad'a ait tuğra bulunmasından dolayı defterin M. 1592 (H.1001) yılına ait olduğu anlaşılmaktadır. ${ }^{10}$ Defter siyakat yazı türü ile yazılmış olup 77 sayfadan meydana gelmektedir.

Çalışmaya konu olan defter, Almanya Arşivi'nde "Munich Collections" da 138 Numara ile kayıtlı mufassal tahrir defteridir. Defter, Sigetvar'a ait nahiye ve köylerin isimleri ile başlamaktadır. Aynı sayfanın alt kısmında, tahrir defterini yazanlar ve yazıldığı tarih yer almaktadır; "Hurre-i bi- kayd-1 bi-emanet-i Ahmed el-fakir mirliva-yı Hatvan sabıka ve bikitabet-i Ahmed el-hakir an kâtibân-1 defter-i Dergâh-1 âlî. Fi gurre-i Şa ‘bani’l-mu'azzam sene seb'a ve semânin ve tis'a-mi'e". ${ }^{11}$ Daha sonra gelen beş sayfa boştur. Bu sayfalardan sonra Sigetvar livasına ait yedi sayfadan müteşekkil kanunnâme ${ }^{12}$ bulunmaktadır. Defter siyakat yazı türü ile yazılmış olup 141 varaktan oluşmaktadır.

Çalışmanın özgünlüğü, bu nevi bir araştırma için dönemin ana kaynağı sayılan tahrir defterlerini analiz etmesinde yatmaktadır. Üzerinde çalıştığımız 138 Numaralı mufassal tahrir defteri daha önce çalışılmamış, yalnızca Münir Aktepe tarafından Sigetvar kanunnamesi ayrıntıları ile anlatılmıştır. Sigetvar Nahiyesi’ne dair incelendiği şekilde daha önce herhangi bir çalışmanın bulunmaması araştırmanın önemini artırmaktadır.

\section{1. İdari Yapı ve Nüfus}

Sigetvar, 1566 yılında Osmanlı idaresine geçmiş ve Osmanlı Devleti’nin batı sınırında Sigetvar Sancağı teşkil edilmiştir. ${ }^{13}$ Sancak bu tarihte Budin Eyaleti'nin bağlı idari bir birim idi. Fetihten sonra sancağın ilk tahriri 1570 yılında yapılmıştır ve sancakta ilk alaybeyi olarak Peçuy alaybeyi İskender Bey görevlendirilmiştir. ${ }^{14}$ Sigetvar' 1 fethinde sonra tutulan ilk tahrir defterinde yararlılığı görülen mirliva, zuema ve sipah (asker) zümresinden kişilere tımar verilmesi istenilmiştir. ${ }^{15} \mathrm{Bu}$ dönemde Sigetvar mirlivası Sinan Bey has ${ }^{16}$, miralay Mehmed ${ }^{17}$, kapdan-1 nehir Malkoç, Hüsrev bin Yusuf ve Kurd zeamet tasarruf edenler arasındadır. Tımarlar ise serasker $\mathrm{Abdi}^{18}$ ve görevleri hakkında bilgi bulunmayan Ali Ağa ve Nasuh bin Hüseyin gibi kişilere verilmiştir.

Sigetvar Sancağı, 1579 Budin Eyaleti’ne bağlı bir sancak olup, bu tarihte Görezgal, Şikloş ve Harşan Nahiyeleri'nden meydana gelmiştir ${ }^{19}$. Kanije'nin 1600 yılında fethedilmesiyle birlikte yeni bir eyalet merkezi olan Kanije Eyaleti’nin kurulmuş ve Sigetvar Sancağı bu eyalete bağlı

10 Cumhurbaşkanlığı Devlet Arşivleri Başkanlığı Osmanlı Arşivi (BOA), Tapu Tahrir Defterleri (TT.d), 638,1.

11 Aumer, Türkische Handschriften.(BSB Cod.turc.), 138, 8.

12 Sigetvar Kanunnamesi'nin çevirisi Münir Aktepe tarafından yapılmıştır. Bkz. Münir Aktepe, "Szigetvar Livâsı Kanun-Nâmesi”, Kanunî Armağanı, (Ankara: TTK Yay., 1970), 187-202.

13 Cumhurbaşkanlığı Devlet Arşivleri Başkanlığı Osmanlı Arşivi (BOA), Tapu Tahrir Defterleri (TT.d), 503.

14 Aktepe, "Szigetvar Livâsı Kanun-Nâmesi”, 189.

15 BOA, TT.d, 503,4.

16 BOA, TT.d, 503,7.

17 BOA, TT.d, 503, 503,9.

18 BOA, TT.d, 503,12.

19 Aumer, Türkische Handschriften.(BSB Cod.turc.), 138, 1. 
bir sancak haline getirilmiştir. ${ }^{20} 1688$ yılında Osmanlı hâkimiyeti son bulan Sigetvar, bu yıla kadar idari olarak Kanije Eyaleti'ne bağlı sancak olarak kalmıştır. ${ }^{21}$

Tahrir defterlerinden edinilen bilgiler ışığında, 1579'da Sigetvar Sancağı'nın idarî yapısının, esas itibarıyla "nahiye” esasına göre teşkilatlandırıldığı söylenebilir. ${ }^{22}$ Bu çalışmada Sigetvar Sancağı'nın merkez nahiye konumundaki Sigetvar Nahiyesi ele alınmıştır. 1579 yılında Sigetvar Nahiyesi'nde 63 köy, 1 çiftlik ve 11 baştina ${ }^{23}$ kaydedilmiştir. Çiftlik sahibi “der yed-i Yusuf Sipahi ber mûceb-i asker sâhib-i arz ve hüccet-i şer 'iyye"24 ifadesinden anlaşıldı̆̆ 1 üzere Yusuf'tur. Müslüman ve gayrimüslimlerin tasarrufunda bulunan baştinalar mevcuttur. Müslümanlar beş baştina (Behram ${ }^{25}$, Behram bin Abdullah ${ }^{26}$ ve İlyas Divane ${ }^{27}$, Mustafa bin Mehmed $^{28}$ ), gayrimüslimler ise altı baştina tasarruf etmektedirler.

Nahiyede toplam 409 mücerred ${ }^{29}, 1$ bive $^{30}$ ve 762 hane mevcuttur. Osmanlı Klâsik Dönemi nüfusu üzerinde yapılan çalışmalardan hane sayısının hesaplanması ile ilgili çeşitli hesaplama yöntemleri vardır. Bu hesaplama yöntemlerinden en çok kabul edilen Ömer Lütfi Barkan’ın uyguladığı vergi hanesinin 5 rakamı ile çarpılmasıdır. ${ }^{31}$ Bu çalışmada da aynı yöntemle (hane x 5=tahmîni nüfus) Sigetvar Nahiyesi'nin tahmini nüfusu tespit edilmeye çalışılmıştır. Bu hesaplama yöntemine göre Sigetvar Nahiyesi’nin tahmini gayrimüslim nüfus 3.810 olarak tespit edilmiştir. Ayrıca nahiyede 4 Müslüman da bulunmaktadır. Bunlardan Kostancı Köyü’nde bulunan 3 Müslüman'ın baba adının Abdullah ${ }^{32}$ olması bu kişilerin sonradan Müslüman olduğunu akıllara getirmektedir. Çünkü baba adları Abdullah olan reâyanın büyük bir kısmının ihtidâ ederek Müslümanlığa geçtiği bilinmektedir.

20 David Geza, "Kanije”, İslâm Ansiklopedisi, 24, (İstanbul: Türkiye Diyanet Vakfı Yay., 2001), 307.

21 Sadık Müfit Bilge, "Macaristan'da Osmanlı Hâkimiyetinin ve İdari Teşkilatının Kuruluşu ve Gelişmesi”, Osmanlı Tarihi Araştırma ve Uygulama Merkezi Dergisi (OTAM), 11, (Ankara: 2000), 74.

22 Nahiye, Osmanlı Devleti'nde askerî ve idarî bir ünite olarak XV. yüzyıldan itibaren görülmeye başlanmıştır. Bkz. İlhan Şahin, "Nâhiye", İslâm Ansiklopedisi, 32, (İstanbul: Türkiye Diyanet Vakfı Yay., 2006), 307. Bu yüzyılda bir livanın, büyük yerleşim birimleri ile bunlara bağlı diğer yerleşim birimlerini ifade ettiği, bazen de bu yerleşim birimlerine tabi olan alanlar için kullanıldığg görülmektedir. Bkz. İlhan Şahin, "Nâhiye", İslâm Ansiklopedisi, 32, (İstanbul: Türkiye Diyanet Vakfı Yay., 2006), 307. Sancakta, nahiyeleri oluşturan bir alt idarî birim ise köy, mezra, aşiretler ve çiftliklerdir.

23 Baştina: Osmanlı Devleti’nde gayrimüslimlerin tasarrufunda bulunan çiftliklerdir. Ancak, baştinalar zaman içerisinde Müslümanların eline geçebilmekteydi. Bkz. Feridun Emecen, "Baştina" İslâm Ansiklopedisi, 5, (İstanbul: Türkiye Diyanet Vakfi Yay., 1992), 136.

24 BSB Cod.turc. 138, 8.

25 Behram'ın ölümünden sonra baştina, oğulları Kurd Ali ve Hüseyin'e intikal etmiş ve baştina bunlar üzerine kaydedilmiştir. BSB Cod.turc. 138, 9.

26 Behram bin Abdullah iki baştina tasarruf etmektedir. BSB Cod.turc. 138, 11.

27 BSB Cod.turc. 138, 18.

28 BSB Cod.turc. 138, 21.

29 Mücerred: Bekâr erkeklere denir. Bkz. Halil İnalcık, Hicri 835 Tarihli Sûret-i Defter-i Sancak-i Arvanid, (Ankara: Türk Tarih Kurumu Yay., 1987), XXXIII.

30 Bive, evi olan dul kadına denir. Bkz. Halil İnalcık, Hicri 835 Tarihli Sûret-i Defter-i Sancak-i Arvanid, s.XXXIII.

31 Ömer Lütfi Barkan, "Tarihi Demografi Araştırmaları ve Osmanlı Tarihi”, Türkiyat Mecmuası, X, (İstanbul: 1953), 12.

32 BSB Cod.turc. 138, 12. 
Osmanlı Devleti'nin Balkan coğrafyasında olduğu gibi iskân politikası çerçevesinde Sigetvar'a Türk nüfusu yerleştirmediği görülmektedir. Zira Sigetvar Nahiyesi’nde bulunan 3 Müslümanın baba adının “Abdullah” olması bu kişilerin sonradan Müslümanlığı tercih ettiğini ve herhangi bir iskâna tabi tutulmadığını göstermektedir. İncelenen deferde nahiyenin iskâna tabi tutulduğuna dair herhangi bir bilgi mevcut değildir.

İncelenen defterin 8. sayfasından itibaren köy, nüfus ve vergiler kaydedilmeye başlanmış ancak sayfanın "hasıl" ile başlaması, defterin bir sayfasının eksik olduğunu göstermektedir. Bu nedenden dolayı defterde nahiyenin merkezi ile ilgili herhangi bir bilgi mevcut değildir.

\section{2. İktisadi Yapı}

\subsection{Vergiler}

Osmanlı Klâsik Döneminde reayadan alınan vergiler genellikle iki kısımda incelenir. İlk kısımdaki vergiler zirâi, ticarî ve sınaî gibi üretime dayalı faaliyetler sebebiyle aynî ve nakdî olarak toplanan vergilerdir. ${ }^{33}$ İkincisi ise raiyyet rüsumu ile ârızî vergilerden oluşmaktadır. Raiyyet rüsumu, kişinin sahip olduğu duruma ve tasarrufu altında bulunan toprağa göre alınır. Arızî vergiler ise miktarı önceden belli olmayan, durum ve şartlara göre alınan vergilerdir. Vergi türleri ve vergi oranları bölgeden bölgeye değiştiği için Osmanlı Devleti genel itibarıyla her bölgeye ait bir kanunname düzenlerdi. Osmanlı'nın Sigetvar'da tatbik etmiş olduğu vergi düzeni, üzerinde çalışılan 138 Numaralı mufassal tahrir defterinde Liva-i Kanunname-i Sigetvar başlığı altında bulunmakta ve bu nedenle Sigetvar'a ait vergi türleri ayrıntıları ile mevcuttur. ${ }^{34}$

\subsubsection{Tarım ve Hayvancılık}

Osmanlı Devleti'nde ziraî alanda ekonominin temel unsurunu tarım ürünleri oluşturmaktadır. Sigetvar Nahiyesi'nde gelirin büyük bir bölümü tarımsal ürünlerden elde edilmekteydi. Tahrir defterlerinde bilindiği üzere sadece vergiye tabi olan tarım ürünleri kaydedilmekteydi. Defterde yer alan Sigetvar Kanunnamesi’nde bu durum açıkça belirtilmiştir. Buna göre evin yanında bahçesi olan ve yemek için ektiği maydanoz ve sair sebzevat gibi satılığı olmayan nesnelerden vergi alınmayacağı belirtilmiştir. ${ }^{35}$ Ancak bu sebzevat pazarda satılacaksa ondan da vergi alınması kanunnamede açıkça ifade edilmiştir. Bu cümle itibarıyla, tahrir defterlerindeki veriler değerlendirilirken sadece vergiye tabi olan tarım ürünleri ele alınmıştır.

Kanunnameye göre Sigetvar'da üretilen her türlü hububatta kullanılan ölçü birimi kiledir. Diğer yandan, tarım ürünleri değerlendirilirken üzerinde durmamız gereken bir başka hususta; deftere kaydedilen ürün miktarlarının kile cinsinden kilogram hesabına çevrilmesidir. Bilindiği üzere Osmanlı Devleti’nde kile olarak kullanılan ölçü birimi eyaletlere göre değişiklik

33 Sıddık Çalık, Çirmen Sancă̆ı Örneğinde Balkanlar'da Osmanlı Düzeni (15.-16. Yüzyıllar), (Ankara: BosnaHersek Dostları Vakfı Yay., 2005), 15.

34 BSB Cod.turc. 138, 2-b-5-b.

35 BSB Cod.turc. 138, 2. 
göstermektedir ve genellikle İstanbul kilesi kullanılmakta ve bu 25,658 kilograma karşılık gelmektedir. ${ }^{36}$ Ancak Macaristan'da farklı kileler kullanılmış ve bu nedenle 1579 yılında bir ferman çıkarılarak kile 30 okkaya sabitlenmiştir. ${ }^{37}$

Buğday: İncelenen defterde buğday "hınta" olarak kaydedilmiştir. Buğday, Sigetvar Nahiyesi’nde tarım ürünleri içerisinde en çok yetiştiriciliği yapılan üründür. Nahiyede buğdayın kilesinden alınan vergi miktarı 13 akçe olup nahiyede 1579 yılında toplam 6.000 kile buğday üretilmiştir. Buğday öşründen elde edilen gelir miktarı 78.000 akçe olarak kaydedilmiştir.

Mahlut: Buğdaydan sonra en çok yetiştirilen ürün mahluttur. Mahlut, buğday ve çavdar karışımı bir tahıl çeşididir. ${ }^{38}$ Nahiyede toplamda 3.341 kile mahlut üretilmiştir. Mahlutun kilesi 9 akçe olup mahluttan nahiye genelinde toplam 30.069 akçe gelir kaydedilmiştir.

Kelem, Sir ve Piyaz: Kelem lahana demek olup, nahiyede kelemden alınan vergi miktarı 2.672 akçedir. Sir sarımsak, piyaz soğan demektir. Bu ürünlerden Sigetvar Nahiyesi’nde toplam 1.660 akçe vergi alınmıştır.

Giyah: Bilindiği üzere giyah çayırdan biçilen otttan alınan vergidir. Giyahtan nahiye genelinde toplam 14.798 akçe gelir kaydedilmiştir.

Keten ve Kendir: Keten tohumunun çeşitli ev ilaçlarında kullanılmasının yanı sıra, bazı bölgelerde yemeklerde yağ olarak kullanıldığ 1 ve kendirlerinden de ip, urgan ve keten bezi imal edildiği bilinmektedir. ${ }^{39}$ Nahiyede toplam 18.164 akçe gelir alınmıştır.

Bostan ve Meyve: Nahiye genelinde bostandan alınan gelir 1.464 ve meyveden alınan gelir ise 247 akçedir.

Bă̆cılık: Nahiyede bağcılığın pek yaygın olmadığını görüyoruz. Nahiyede toplam 600 akçe vergi alınmıştır.

Resm-i Bellut: Pelit anlamına gelip ${ }^{40}$, Sigetvar'da bu vergi kaleminden toplam 1.823 akçe gelir elde edilmiştir.

Sigetvar Nahiyesi'nde hayvancılık faaliyetlerini defterdeki vergi tasnifine göre küvvare ve henâzır başlığı altında toplamak mümkündür.

$\ddot{O}_{s ̧ r-i}$ Küvvare: Kovan resmi olarak bilinen küvvare, arı kovanlarından alınan vergidir. Sigetvar Livas1 Kanunnamesi'nde “on kovandan bir kovan alına, on kovan olmayacak her kovan başına ikişer akçe alına" ifadesi ile öşr-i küvvareden alınacak akçe miktarı belirtilmiştir. 1576 y1lında nahiyede toplam bal üretiminden 7.250 akçe gelir elde edilmiştir.

Bad-i Henâzır: Henâzır yani domuz yetiştiriciliğinden alınan vergi miktarı, Sigetvar kanunnamesinde açıkça belirtilmiştir "resm-i henâzır için üzerlerine yıl geçmişinden iki akçe

36 Kile, genellikle kuru meyve ve hububat ölçümünde kullanılan bir ölçek olup, Osmanlı Devleti'nin resmi ölçeği olarak İstanbul kilesi 25,7 kg'dır. Bk. Cengiz Kallek, "Kile”, İslâm Ansiklopedisi, 25, (Ankara: Türkiye Diyanet Vakfi Yay., 2002), 568-569.

37 Kallek, "Kile", 569.

38 Nurettin Madran, Tarım Sözlüğ̈̈, (Ankara: Ayyıldız Matbaası, 1966), 182.

39 Huricihan İslamoğlu, Osmanlı İmparatorluğu'nda Devlet ve Köylü, (İstanbul: İletişim Yay., 1991), 190.

40 Ömer Lütfi Barkan, XV. ve XVI ıncı Asırlarda Osmanlı Imparatorluğunda Ziraî Ekonominin Hukukî ve Malî Esaslarl, 1 (Kanunlar), (İstanbul: İstanbul Üniversitesi Yay., 2001), 538. 
alına ve yıl geçmeden nesne alınmaz" ifadesi ile bu vergi kaleminden alınan vergi miktarı ve vergi alınma şartı açıkça belirtilmiştir. Sigetvar'da henâzırdan alınan vergi miktarı hatırı sayılır bir oran teşkil etmektedir. Nahiye genelinde henâzır için kaydedilen miktar 11.893 akçedir. Bu miktar, tarım ve hayvancılıktan alınan vergi kalemleri içerisinde beşinci sırada yer almaktadır.

Tablo 1: Tarım ve Hayvancilık Faaliyetlerden Alınan Vergiler ${ }^{41}$

\begin{tabular}{lccc}
\hline TARIM & \multicolumn{3}{c}{ HAYVANCILIK } \\
\hline & Gelir $($ Akçe) & & Gelir $($ Akçe) \\
\hline Buğday & 78.000 & Küvvare & 7.250 \\
Mahlut & 30.069 & Henâzır & 11.893 \\
Keten & 14.025 & & \\
Kelem & 2.672 & & \\
Sir ve Piyaz & 1.660 & & \\
Giyah & 14.025 & & \\
Keten ve Kendir & 4.139 & & \\
Bostan & 1.464 & & \\
Meyve & 247 & & \\
Bağc1lık & 600 & & $\mathbf{1 9 . 1 4 3}$ \\
Orak & 773 & Toplam & \\
Toplam & $\mathbf{1 4 7 . 6 7 4}$ & & \\
\hline
\end{tabular}

\subsubsection{Ticarî ve Sinaî Faaliyetler}

Şehir ve köy yapısını ayıran en önemli özellik ticarî ve sınaî faaliyetlerdir. Bilindiği üzere şehir, nüfusun çoğunluğunun ticaret, sınaî ve yönetim gibi işlerle uğraştığı büyük yerleşim merkezlerine verilen isimdir. ${ }^{42}$ XV. ve XVI. yüzyıllarda Osmanlı Devleti’nde şehir kavramını tanımlayacak kesin bir kıstas yoktur. Genel olarak tahrir defterlerinde, nahiyelerin başında bulunan "nefs" kelimesi nahiye merkezi olarak tanımlanmaktadır. Bu cümle itibarıyla, Sigetvar Nahiyesi'nde incelediğimiz dönemde, üzerinde inceleme yaptığımız defterin ilk sayfasının eksik olmasından dolayı nahiye merkezi ile ilgili bilgi bulunamamıştır.

Ticarî ve sınaî vergilerden ilk olarak inceleyeceğimiz değirmen, defterlerde "resm-i âsiyab" olarak geçmektedir. Sigetvar kanûnnâmesinde "ve Nehr-i Tuna ve Drava üzerinde vâki' olan âsiyabdan elli akçe resm alına ve altı ay yürüyen âsiyabdan yirmi beşer akçe alına” ifadesi ile değirmenden alınan vergi miktarı belirtilmiştir. Buna göre Sigetvar nahiyesinde altı ay çalışan değirmen sayısı beş olup, 1576 yılında bu değirmenlerden toplam 125 akçe vergi alınmasına karar verilmiştir. Nahiyede elli akçe ile çalışan sadece bir değirmene rastlanılmıştır. ${ }^{43}$ Nahiyede değirmenden alınan toplam vergi miktarı 175 akçedir.

Nahiyede diğer önemli bir vergi kalemi de "resm-i hime" dir. Resm-i hime odundan alınan vergi anlamına gelmektedir. Sigetvar nahiyesinde bu kalemden elde edilen toplam vergi miktarı 9.307 akçedir.

41 BSB Cod.turc. 138

42 Mustafa Sabri Küçükaşc1, "Şehir”, İslâm Ansiklopedisi, 38, (İstanbul: Türkiye Diyanet Vakfi Yay, 2010 ), 441.

43 BSB Cod.turc. 138, 13. 
Resm-i Fuçu: Şıra üretimi yapan gayrimüslimler, şıranın onda birini sipahiye vermek zorundaydılar. Sipahi bu şırayı satmak için tımarı dâhilindeki şıra fiçılarını mühürler ve şıra satışını yasaklayarak manapolye ilan ederlerdi. ${ }^{44}$ Bu süre iki ay ila yetmiş beş güne kadar değişirdi. Bu müddet içerisinde sipahi şarabından başka şarap içilmez ve başka şarap alınmazdı ancak reayanın manopolyeden etkilenmemesi için sipahilerin konulan narhtan fazlasına ve monopolye süresi geçtikten sonra geriye kalan şaraplar için narhtan fazlasını satmaları yasaklanmıştır. ${ }^{45}$

Kanunnamede "ve şol varoşun ve karyenin bağları ola iki ay on gün şıraların satılu geldiği üzere manapolye tutulmak kanundur, ziyâde tutulmaya" 46 ifadesi yer almaktadır. Buna göre manapolye olarak adlandırılan bu süreç, kanunnamede belirtildiği üzere iki ay on gündür ve bu süreden daha fazla olamayacağı belirtilmiştir. Fuçudan elde edilen gelir miktarı 1.342 akçe olarak tespit edilmiştir.

\subsubsection{Raiyyet ve Ârizî Vergiler}

Raiyyet vergisi, üretime dayalı olmayan daha çok şahısların hukuki durumuna göre (evli ya da bekâr, Müslim-gayrimüslim) ve tasarruf ettiği toprağa göre alınan vergidir. Sigetvar Nahiyesi'nde bu vergiler şunlardır:

Resm-i Kapu: Bu vergi ispenç vergisi ya da kapu vergisi olarak da adlandırılır. Esas itibarıyla, şehirli ve köylü bulûğ çağına ermiş her gayrimüslim erkeğin, Müslümanların çift vergisine mukabil ödemek zorunda oldukları bir baş vergisidir. ${ }^{47}$ Kapu vergisi ile ilgili kanunnamede "Resm-i kapu dedikleri ispençe mukabilinde her hâneden sipahisine Hızır İlyas gününde yirmi beşer akçe ve Kasım gününde dahi yirmi beşer akçe vereler" ${ }^{48}$ hükmü ile kapu vergisinin miktarı ve ne zaman toplanacağı belirtilmiştir. Buna göre bu vergi yılda 50 akçe olarak belirtilmiştir. Sigetvar Nahiyesi'nde 762 haneden toplam 38.100 akçe kapu vergisi alınmıştır.

Resm-i Çift: Bu resim, çiftlik tasarruf eden Müslümanlardan alınan şahsi bir vergidir. Çift vergisi, toprağın verim kabiliyetine göre 60 ilâ 150 dönüm arasındaki değişen arazi parçasını ifade eder. ${ }^{49}$ Böyle bir toprağa sahip olan çiftçi ailesi işlediği bu toprağa karşılık çift resmi denilen vergiyi ödemekle yükümlüdür. ${ }^{50}$ Üzerinde çalıştığımız mufassal tahrir defterinde Kostancı Köyü’nde kayıtlı 3 Müslüman'ın isminin altında “22” yazması bunlardan alınan vergi miktarını da göstermektedir. ${ }^{51} \mathrm{Bu}$ bilgiler 1şığında, Sigetvar Nahiyesi'nde gayrimüslimlerden 50 akçe kapu vergisi, Müslümanlardan ise 22 akçe çift vergisi alınmakta idi. Sigetvar Nahiyesi’nde 4 Müslüman nüfus bulunmakta ve bu vergi kaleminden 88 akçe gelir elde edilmiştir.

44 Coşkun Üçok, "Osmanlı Devleti Teşkilâtında Tımarlar”, Ankara Üniversitesi Hukuk Fakültesi Dergisi, 2/1, (Ankara: 1944), 77.

45 Üçok, "Osmanlı Devleti Teşkilâtında Tımarlar", 77.

46 BSB Cod.turc. 138, 4-a.

47 Halil İnalcık, "Çiftlik", İslâm Ansiklopedisi, 8, (İstanbul: Türkiye Diyanet Vakfı Yay., 1993), XXXII.

48 BSB Cod.turc. 138, 3-a.

49 İnalcık, "Çiftlik", 313.

50 Ferudun Emecen, “Çift Resmi”, İslâm Ansiklopedisi, 8, (İstanbul: Türkiye Diyanet Vakfı Yay., 1993), 309.

51 BSB Cod.turc. 138, 12. 
Ârızî vergileri; Tapu, deştbani, arus ve niyabet adı altında incelenmiştir. Resm-i tapu, toprak parçası el değiştirdiği zaman, zirai faaliyetlerin dışında miri topraklardan maktu olarak alınan vergidir. ${ }^{52}$ Sigetvar Nahiyesi'nde resm-i tapudan alınan vergi miktarı 4.180 akçedir. Âdet- $i$ deştbani, başkasının toprağına hayvan sokarak zarar veren kişiden alınan vergi olup, nahiye genelinde 6.766 akçe vergi alınmıştır. Resm-i arûs vergisi, tımar sahibinin kendi toprağında olan reayadan dügün veya gerdek için aldığg vergidir. ${ }^{53}$ Resm-i arûsdan nahiye genelinde toplam 3.667 akçe vergi alınmıştır. Nahiyede niyabetten alınan vergi ise 8.674 akçedir.

Tablo 2: Raiyyet ve Ârızî Vergiler ${ }^{54}$

\begin{tabular}{lccc}
\hline Arrzzî Vergiler & Vergi Geliri & Raiyyet Vergisi & Vergi Geliri \\
\hline Resm-i Tapu & 4.180 & Resm-i Kapu & 38.100 \\
Âdet-i Deştbani & 6.766 & Resm-i Çift & 66 \\
Resm-i Arûs & 3.667 & & \\
Niyabet & 8.674 & & \\
Toplam & $\mathbf{2 3 . 2 8 7}$ & Toplam & $\mathbf{3 8 . 1 6 6}$ \\
\hline
\end{tabular}

1579 yılında Sigetvar Nahiyesi'ne tabi köylerden elde edilen gelir miktarı toplam 177.766 akçedir.

\section{Sonuç}

Bilindiği üzere XV. ve XVI. yüzyıllarda mahalli araştırmaların temel kaynağını tahrir defterleri oluşturmaktadır. Bu defterler Osmanlı taşra yapısının temelini teşkil eden bir sancağın; idarî, iktisadî, sosyal yapısıyla, iskân sürecini ortaya çıkarmak için başvurulan ilk kaynaklardandır. Bu bağlamda üzerinde çalıştığımız defter Sigetvar'ın ilk mufassal tahrir defteridir ve bu defterde yer alan bilgiler çerçevesinde Osmanlı'nın Sigetvar'da teşkil ettiği düzeni ortaya koymak mümkün olmuştur.

Sigetvar Sancağı, klâsik dönem Osmanlı sancak sisteminin özelliklerini taşımaktadır. Yani, sancakta tahrir yapılmış ve tımar sistemi uygulanmıştır. Sancakta, tahrir defterleri nahiye esas alınarak tutulmuştur. Üzerinde çalışılan Sigetvar Sancağı'nın merkez nahiye durumunda bulunan Sigetvar Nahiyesi'nde 63 köy, 1 çiftlik ve 11 baştina bulunmaktadır.

Sigetvar Nahiyesi'ne tabi köylerin neredeyse tamamında yerleşme bulunmaktadır. 1579 yılında Osmanlı düzeninin Sigetvar Nahiyesi’nde yerleştiği görülmektedir. Nüfusun çoğunluğunu tarım toplumunun bir özelliği olarak kırsal kesim oluşturmaktadır. Nahiyede nüfusun neredeyse tamamı gayrimüslimlerden oluşmaktaydı. Sigetvar Nahiyesi'nde bulunan 3 Müslümanın baba adının "Abdullah” olması bu kişilerin sonradan Müslümanlığı tercih ettiğini ve herhangi bir iskâna tabi tutulmadığını göstermektedir. Nahiyede bölgeye Türk nüfusu yerleştirildiğine dair herhangi bir kayıt mevcut değildir.

52 Ahmet Tabakoğlu, "Resim”, İslâm Ansiklopedisi, 34, (İstanbul: Türkiye Diyanet Vakfı Yay., 2007), 583.

53 Halil Sahillioğlu, “Arûs Resmi”, İslâm Ansiklopedisi, 3, (İstanbul: Türkiye Diyanet Vakfi Yay., 1991), 423.

54 BSB Cod.turc. 138. 
Ayrıca, Sigetvar'a tabi "Varoş-1 Sigetvar ma'a çiftlikhâ ve ispençe-i kıbtıyân” başlığında kayıt da mevcuttur. Burada kayıtlı 45 reayanın baba adının Abdullah olması Müslüman nüfusun önemli bir kısmının ihtidalar sonucu olduğu görülmektedir. ${ }^{55}$ Yine, Mehmed bin Bayezid Mahallesi'nde 14 kişinin $^{56}$ ve Veli bin Ali Mahallesi'nde 12 kişinin baba adlarının Abdullah olması dikkate değer bir rakamdır. ${ }^{57}$

Sigetvar Nahiyesi'nin iktisadî yapısını tarım teşkil etmektedir. Tarımdan elde edilen gelir, nahiye genelinden elde edilen gelirin \% 83'ünü oluşturmaktadır. Tarımdan sonra ikinci sırada raiyyet ve ârızî vergilerden elde edilen gelir yer almakta ve nahiye gelirinin \% 11,5'ini oluşturmaktadır. Ticarî ve sınaî ürünlerinden elde edilen gelir ise \% 5,3 ile üçüncü sırada yer almaktadır.

Hakem Değerlendirmesi: Dış bağımsız.

Çıkar Çatışması: Yazar çıkar çatışması bildirmemiştir.

Finansal Destek: Yazar bu çalışma için finansal destek almadığını beyan etmiştir.

Peer-review: Externally peer-reviewed.

Conflict of Interest: The author has no conflict of interest to declare.

Grant Support: The author declared that this study has received no financial support.

\section{Kaynaklar/References}

\section{Arșiv Kaynakları}

Türkische Handschriften (BSB Cod.turc.) No: 138.

Osmanlı Arşivi (BOA) Cumhurbaşkanlığı Devlet Arşivleri, Osmanlı Arşivi Daire Başkanlığı, Tapu Tahrir Defterleri ( TT.d), No: 503.

Osmanlı Arşivi (BOA) Cumhurbaşkanlığı Devlet Arşivleri, Osmanlı Arşivi Daire Başkanlığı, Tapu Tahrir Defterleri ( TT.d), No: 638.

Osmanlı Arşivi (BOA) Cumhurbaşkanlığı Devlet Arşivleri, Osmanlı Arşivi Daire Başkanlığı, Mühimme Defterleri (A.DVNSMHM), No: 5.

\section{Kitap ve Makaleler}

Aktepe, Münir, “Szitgetvar Livâsı Kanûn-nâmesi”, Kanunî Armă̆anı, Ankara: TTK Yay (1970): 187-202.

Barkan, Ömer Lütfi. “Tarihi Demografi Araştırmaları ve Osmanlı Tarihi”. Türkiyat Mecmuası. X. İstanbul (1953):1-25. XV. ve XVI ıncı Astrlarda Osmanlı Imparatorluğunda Zirầ Ekonominin Hukukî ve Malî Esaslarl, 1, İstanbul: İstanbul Üniversitesi Yay., 2001.

Bilge, Sadık Müfit Bilge, "Macaristan’da Osmanlı Hâkimiyetinin ve İdari Teşkilatının Kuruluşu ve Gelişmesi ”, Osmanlı Tarihi Araştırma ve Uygulama Merkezi Dergisi (OTAM), Ankara (2000): 33-81.

55 BSB Cod.turc. 138, 42-b-44-a.

56 BSB Cod.turc. 138, 44-b.

57 BSB Cod.turc. 138, 42-b-45-a. 
David, Geza. “Kanije”. İslâm Ansiklopedisi. 24, İstanbul: Türkiye Diyanet Vakfi Yay (2001): 307-308. "Sigetvar". İslâm Ansiklopedisi. 37. İstanbul: Türkiye Diyanet Vakfı Yay. (2009): 157-159.

Emecen, Feridun. “Çift Resmi”. İslâm Ansiklopedisi. 8. İstanbul: Türkiye Diyanet Vakfı Yay. (1993): 309-310. "Baştina” İslâm Ansiklopedisi. 5. İstanbul: Türkiye Diyanet Vakfı Yay. (1992): 135-136.

İnalcık, Halil. Hicri 835 Tarihli Sûret-i Defter-i Sancak-i Arvanid, Ankara: Türk Tarih Kurumu Yay., 1987. "Çiftlik". İslâm Ansiklopedisi. 8. İstanbul: Türkiye Diyanet Vakfı Yay. (1993): 313-314.

Feridun Ahmed Bey, Nüzhet-i Esrârü'l-Ahyâr Der-Ahbâr-ı Sefer-i Sigetvar / Sultan Süleyman'ın Son Seferi, Hazırlayan: H. Ahmet Arslantürk-Günhan Börekçi, İstanbul: Zeytinburnu Belediyesi Kültür Yayınları, 2012. İslamoğlu, Huricihan. Osmanlı İmparatorluğu’nda Devlet ve Köylü, İstanbul: İletişim Yay., 1991.

Kallek, Cengiz. "Kile”. Íslâm Ansiklopedisi. 25. Ankara: Türkiye Diyanet Vakfı Yay.(2006): 568-571.

Küçükaşçı, Mustafa Sabri. “Şehir”. İslâm Ansiklopedisi. 38. İstanbul: Türkiye Diyanet Vakfi Yay. (2010): 441-446.

Lowry, Heath W., Trabzon Şehrinin Íslamlaşması ve Türkleşmesi 1461-1583, çev. Demet ve Heath Lowry, İstanbul: Boğaziçi Üniversitesi Yay., 1998.

Madran, Nurettin. Tarım Sözlüğ̈̈, Ankara: Ayyıldız Matbaası, 1966.

Naç, Kübra. Âgehî’nin Fetih-nâme-i Kal'a-i Sigetvar’1 (İnceleme-Tenkitli Metin), Basılmamış Yüksek Lisans Tezi, Fatih Üniversitesi Sosyal Bilimler Enstitüsü, İstanbul: 2013.

Önal, Ahmet. Kanunî’nin Son Seferi (Sigetvar 1566), İstanbul: Yeditepe Yayınevi, 2019.

Peçevi İbrahim Efendi. Peçevi Tarihi I, Hazırlayan: Bekir Sıtkı Baykal, Ankara: Kültür Bakanlığı Yayınları, 1992.

Selânikî Mustafa Efendi. Tarih-i Selânikî I (971-1003/1563-1595), Hazırlayan: Mehmet İpşirli, Ankara: TTK Yayınları, 1999.

Şemseddin Sami. Kâmus-ı Alâm, 4. İstanbul: Mihran Matbaası, 1311.

Sahillioğlu, Halil. “Arûs Resmi”. İslâm Ansiklopedisi. 3. İstanbul: Türkiye Diyanet Vakfı Yay. (1991): $422-423$.

Şahin, İlhan. "Nâhiye”. İslâm Ansiklopedisi. 32. İstanbul: Türkiye Diyanet Vakfı Yay. (2006): 306-308.

Tabakoğlu, Ahmet. "Resim”. İslâm Ansiklopedisi. 34. İstanbul: Türkiye Diyanet Vakfi Yay. (2007): 582-584. Uzunçarşılı, İsmail Hakkı,.Osmanlı Tarihi, II. Ankara: TTK Yay., 1983.

Üçok, Coşkun. “Osmanlı Devleti Teşkilâtında Tımarlar”. Ankara Üniversitesi Hukuk Fakültes Dergisi. $2 / 1$. Ankara (1944): 525-551. 
